\section{Heat load and deuterium plasma effects on SPS and WSP tungsten}

\author{
Monika Vilémová, \\ Jiř́i Matějíček, \\ Barbara Nevrlá, \\ Maryna Chernyshova, \\ Pawel Gasior, \\ Ewa Kowalska-Strzeciwilk, \\ Aleš Jäger
}

\begin{abstract}
Tungsten is a prime choice for armor material in future nuclear fusion devices. For the realization of fusion, it is necessary to address issues related to the plasma-armor interactions. In this work, several types of tungsten material were studied, i.e. tungsten prepared by spark plasma sintering (SPS) and by water stabilized plasma spraying (WSP) technique. An intended surface porosity was created in the samples to model hydrogen/ helium bubbles. The samples were subjected to a laser heat loading and a radiation loading of deuterium plasma to simulate edge plasma conditions of a nuclear fusion device (power density of $10^{8} \mathrm{~W} / \mathrm{cm}^{2}$ and $10^{7} \mathrm{~W} / \mathrm{cm}^{2}$, respectively, in the pulse intervals up to $200 \mathrm{~ns}$ ). Thermally induced changes in the morphology and the damage to the studied surfaces are described. Possible consequences for the fusion device operation are pointed out.
\end{abstract}

Key words: tungsten $\bullet$ fusion $\bullet$ heat loading $\bullet$ irradiation $\bullet$ bubbles $\bullet$ surface damage

M. Vilémová ${ }^{\bowtie}$ J. Matějíček, B. Nevrlá

Institute of Plasma Physics ASCR,

Za Slovankou 1782/3, 18200 Prague 8, Czech Republic,

E-mail: vilemova@ipp.cas.cz

M. Chernyshova, P. Gasior, E. Kowalska-Strzeciwilk Institute of Plasma Physics and Laser Microfusion (IPPLM),

23 Hery Str., 01-497 Warsaw, Poland

\section{A. Jäger}

Laboratory of Nanostructures and Nanomaterials, Institute of Physics,

Na Slovance 2, 18221 Prague 8, Czech Republic

Received: 22 June 2014

Accepted: 31 October 2014

\section{Introduction}

Plasma facing components in future fusion devices will be subjected to heat and particle loading (neutrons, electrons, hydrogen isotope ions and helium ions). For such a harsh environment tungsten appears to be the most relevant material, especially due to its low sputtering yield and low tritium retention. In future devices tungsten will be used for fabrication of divertor plates and most likely for the first wall armor as well. Of all the plasma facing components, divertor will be exposed to the most severe conditions. Serious risk for the divertor comes from abnormal events, such as disruptions, vertical displacement events (VDEs) and edge localized modes (ELMs). The transient loading can deposit large energies on the divertor surface (power density $\sim \mathrm{GW} / \mathrm{m}^{-2}$ ) within a period of few ms $[1,2]$. The transient loading might cause serious damage to the material, including structural changes such as re-crystallization (in the case of tungsten at temperatures above $1100^{\circ} \mathrm{C}$ ), grain growth, melting, cracking, and erosion. The material reaction to the loading is related to basic properties such as strength, hardness, the thermal conductivity, the thermal expansion and the melting point. The melting conditions for tungsten have been widely studied [3-6]. Thus, it is known that ELM-like cycling causes roughening and surface cracking even if the pulse energy is well below the melting threshold. The surface cracking is frequently 
observed on tungsten surfaces exposed to transient heat fluxes causing significant degradation of mechanical properties. The onset of cracking and crack propagation might be delayed by using alloys with elements such as tantalum or lanthanum-oxide [4, 7] or by reinforcing the structure using fibers [8]. Nevertheless, the issue of tungsten melting under transition heat loading for ITER relevant condition remains still an open question.

Structure degradation is foreseen even during steady-state operation conditions of a fusion device. For example, it is well known that irradiation of a material by hydrogen and helium isotopes causes characteristic changes in the material microstructure such as formation of bubbles and blisters. In the case of tungsten hydrogen blisters appear at temperatures below $600^{\circ} \mathrm{C}$ and at fluence higher than about $10^{24} \mathrm{~m}^{-2}$. The saturation of helium atoms leads to the formation of bubbles as well. Depending on the irradiation conditions, bubbles ranging from several tens of nanometers up to micron in size can develop in the material $[9,10]$. Moreover, with increasing temperature (above $700^{\circ} \mathrm{C}$ ) and fluence approximately $10^{25} \mathrm{~m}^{-2}$ a nanostructure called helium/tungsten 'fuzz' starts to develop [11]. The development of such a surface structure significantly affects the mechanical and thermal properties of the material. As a result, the behavior of the bubble-containing surfaces during transient heat loadings is different from as-manufactured surfaces. The combined effect of heat loading and the presence of hydrogen/ helium induced bubbles could accelerate the onset of surface damage and increase the erosion rate. Some studies confirm the detrimental effect of such a combination; however, some experiments report alleviation of surface damage by transient loadings [12]. Therefore, more detailed studies have to be performed to eliminate the uncertainty in the behavior of irradiated tungsten surface.

In the experiments reported here several types of tungsten material were studied, i.e. tungsten prepared by spark plasma sintering (SPS) and by water stabilized plasma spraying (WSP) technique. Both techniques offer specific advantages in production process of fusion grade tungsten. The spark plasma sintering is a fast, cost-effective technique that is able to produce materials near the theoretical density. The water stabilized plasma spraying is a technique that is able to produce thick layers of tungsten directly on the structural material, eliminating the need for a joining process. Different levels of surface porosity were created in the samples to model hydrogen/helium bubbles. The samples were subjected to thermal and plasma radiation loading to simulate conditions during transient events.

\section{Experimental setup}

A spark plasma sintering machine SPS 10-4 (Thermal Technology, USA) was used to produce sintered tungsten from powders with average grain size of 2 and $4 \mu \mathrm{m}$ (Osram, CZ). Samples were prepared with surface porosity that was completely polished away to obtain compact samples (samples designated as W2 and W4) or left in the samples to simulate structure created by helium/hydrogen bubbles (samples designated as W2-P and W4-P). The irradiation experiments were performed on samples having a shape of $1 / 4$ of a disk with a diameter of $19 \mathrm{~mm}$. The thickness of the samples was about $2 \mathrm{~mm}$.

The plasma sprayed tungsten (coating) was deposited with the use of a hybrid water/argon stabilized plasma torch WSP $® H$ (Institute of Plasma Physics, CZ). Argon shrouding was applied to suppress coating oxidation [13]. For the irradiation experiments a $1 \mathrm{~cm} \times 1 \mathrm{~cm}$ specimen was cut out of the sprayed piece. The thickness of the coating was about $500 \mathrm{~mm}$. The spraying and sintering parameters are summarized in Table 1.

The thermal diffusivity was measured at 100, 400, 500,700 and $900^{\circ} \mathrm{C}$ by a laser-flash method using a FL-3000 machine (Anter, USA) under a nitrogen atmosphere. The hardness was evaluated on a universal hardness tester Nexus 4504 (Innovatest, NL) using Vickers indenter and load equivalent to $100 \mathrm{~g}$. The microstructure, the surface morphology and the damage induced in the samples was evaluated using SEM EVO MA 15 (Carl Zeiss SMT, D) and SEM Quanta 3D FEG (FEI, USA) fitted with a focus ion beam (FIB).

In laboratory conditions the behavior of plasma facing materials under pulsed heat fluxes is simulated by a laser or an electron beam irradiation or irradiation induced by pulsed plasma generators. The ablation results might differ among the simulation methods due to the specific incident species (photons, electrons, plasma) and as such they might not fully cover the complex conditions in a real fusion device. In the presented study samples were subjected to laser thermal loading and plasma radiation loading in order to broaden the field of possible interactions and describe possible differences. Laser irradiation was delivered in pulses provided by the Nd:YAG Q-switched laser system at its fundamental wavelength $(1064 \mathrm{~nm})$, with the energy in the range

Table1. Processing parameters of tungsten samples

\begin{tabular}{lcccc}
\hline Sample & $\begin{array}{c}\text { Powder size } \\
{[\mu \mathrm{m}]}\end{array}$ & $\begin{array}{c}\text { Procesing } \\
\text { technology }\end{array}$ & $\begin{array}{c}\text { Processing } \\
\text { parametres }\end{array}$ & Surface porosity \\
\hline W2 & $1.8-2.2$ & $\mathrm{SPS}$ & $1800^{\circ} \mathrm{C} / 5 \mathrm{~min} / 60 \mathrm{MPa}$ & minor \\
W2-P & $1.8-2.2$ & $\mathrm{SPS}$ & $1800^{\circ} \mathrm{C} / 5 \mathrm{~min} / 60 \mathrm{MPa}$ & major \\
W4 & $3.8-4.3$ & $\mathrm{SPS}$ & $1800^{\circ} \mathrm{C} / 5 \mathrm{~min} / 60 \mathrm{MPa}$ & minor \\
W4-P & $3.8-4.3$ & $\mathrm{SPS}$ & $1800^{\circ} \mathrm{C} / 5 \mathrm{~min} / 60 \mathrm{MPa}$ & major \\
W-WSPH & $60-83$ & $\mathrm{WSP}^{\circledR} \mathrm{H}$ & $\mathrm{FD}=25 \mathrm{~mm}, I=500 \mathrm{~A}$, & volume porosity \\
\hline
\end{tabular}


of $100 \mathrm{~mJ}$ and the duration of $10-12 \mathrm{~ns}$, focused to a spot $2-3 \mathrm{~mm}$ in diameter. It resulted in a power density in the range of $10^{8} \mathrm{~W} / \mathrm{cm}^{2}$. This part of the experiment was intended to simulate localized high intensity interactions of a very short timescale which are relevant for laser-based methods of fuel removal and cleaning. On the other hand, the local damage due to short lasting high-intensity interaction can be used to simulate the damage that could result from a large number of lower intensity events. A plasma focus device PF-6 (Institute of Plasma Physics and Laser Microfusion, PL) was used as a high temperature deuterium plasma generator. The samples were irradiated by 4 pulses at the distance of $8 \mathrm{~cm}$ from the anode. Besides deuterium plasma, tungsten surfaces were subjected to a repeated irradiation by deuteron, electron, neutron and X-ray beams. Nevertheless at the chosen anode-target distance the plasma-induced surface modifications are dominant. The density of power flux from the plasma was estimated to be approximately $10^{7} \mathrm{~W} / \mathrm{cm}^{2}$ and of the ion beam $10^{10} \mathrm{~W} / \mathrm{cm}^{2}$. The

a)

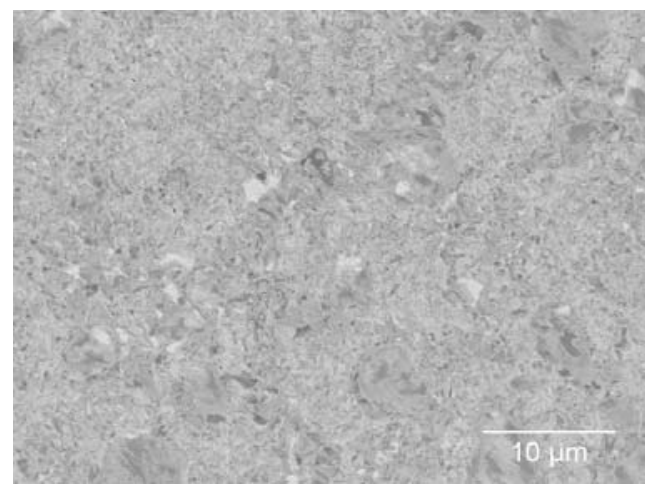

b)

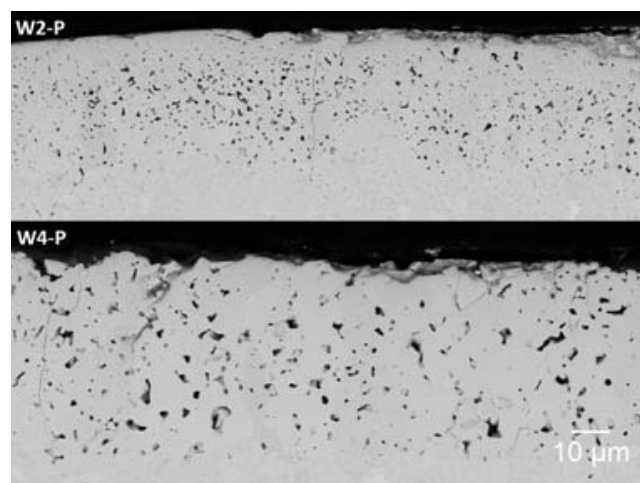

c)

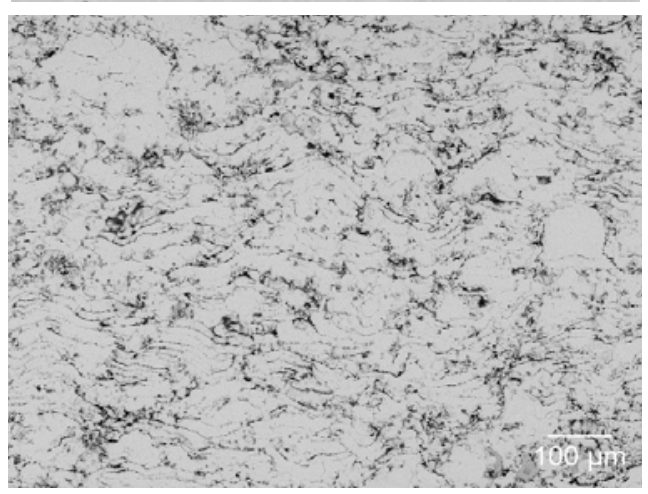

whole surface of the sample was exposed to the plasma stream whereas the ion beam irradiated a spot $2-3 \mathrm{~mm}$ in diameter. The duration of the plasma within a single pulse was about $200 \mathrm{~ns}$.

\section{Experimental results}

A microstructural overview of the tungsten samples is presented in Fig. 1. The sintered tungsten samples, i.e. W2 and W4, showed no apparent difference in the microstructure, thus only W2 sample is documented. Microstructure of the W2/W4 samples consists of fine tungsten grains. The different gray level areas in the micrograph can be attributed to the different grain orientation. The structure is dense, only minor residual porosity remains in the vicinity of the surface (Fig. 1a, right). The porosity was determined to be $0.2 \%$ and $0.3 \%$ for the $\mathrm{W} 2$ and $\mathrm{W} 4$ samples, respectively.

Figure $1 \mathrm{~b}$ shows W2-P and W4-P sample containing surface porosity. The figure depicts the original
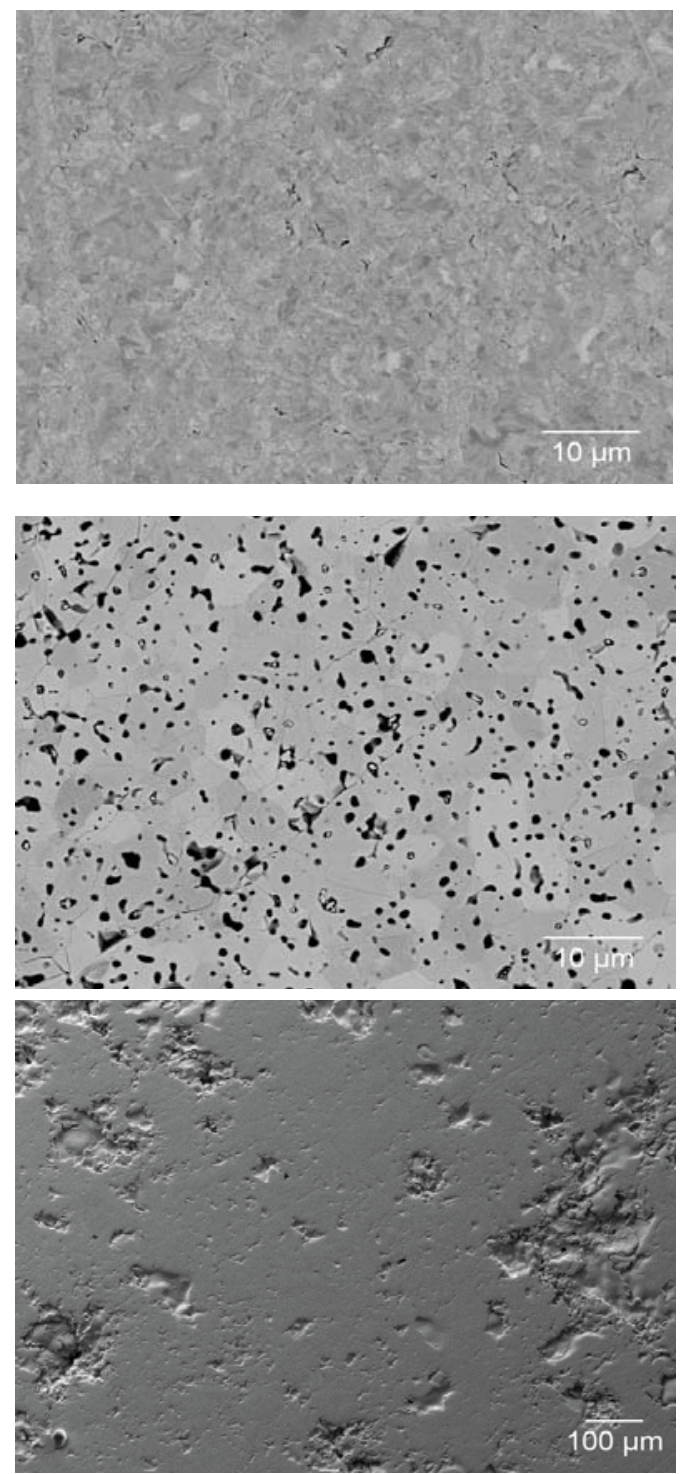

Fig. 1. The microstructure of the tungsten samples. a) W2: the cross section (left) and the polished surface (right); b) W2-P, W4-P: the cross section (left) and the polished surface of W2-P (right); c) W-WSPH: the cross section (left) and the polished surface (right). 
thickness of the layer with pores; however, for the irradiation experiments, the thickness was polished down to few microns to create islands of porosity on the sample surface. Thus, a direct comparison of the irradiation effect on the tungsten surface with and without porosity is made possible. The surface layers of the W2-P and W4-P contain pores mainly in the micron and submicron range. It is apparent that the density of the pores is lower for W4-P than W2-P; however, the average pore size is larger for W4-P. The porosity aims to model the bubble structure observed after irradiation of a material with hydrogen or helium. The size, shape and density of the pores are very close to the commonly reported values for helium bubbles [9].

The microstructure of the W-WSPH sample represents a characteristic structure of plasma-sprayed coating on the cross section consisting of flattened particles ('splats'), intersplat boundaries/cracks/ pores and intrasplat cracks/pores. The relief of the coatings surface (Fig. 1c, right) is an artifact of the polishing process that removed weakly bonded splats from the coating surface.

The evolution of the thermal conductivity with temperature is described in Fig. 2. Although the thermal conductivity of the surface layer of W2-P and W4-P samples is decreased by the pore content, the effect on the overall conductivity of the samples is not significant. Moreover, a slight difference between the sintered samples practically disappears at high temperature.

The surface hardness of the samples before and after irradiation in PF-6 is summarized in Table 2.

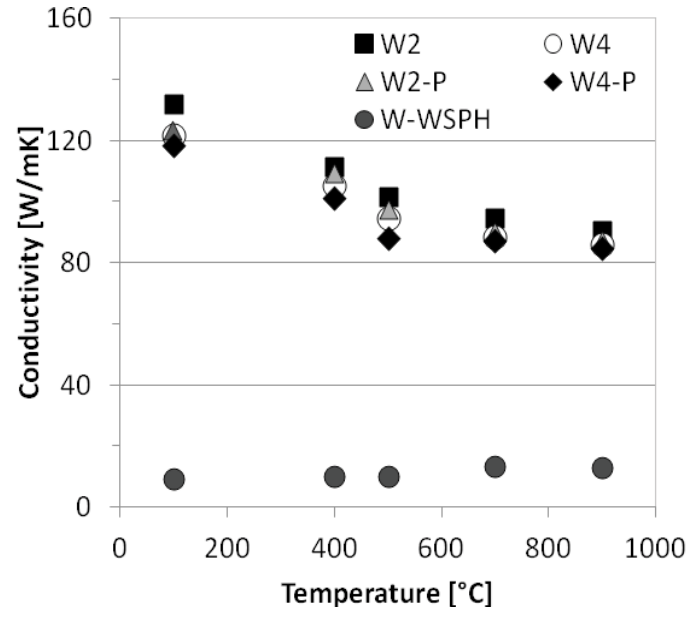

Fig. 2. Thermal conductivities of the tested samples.

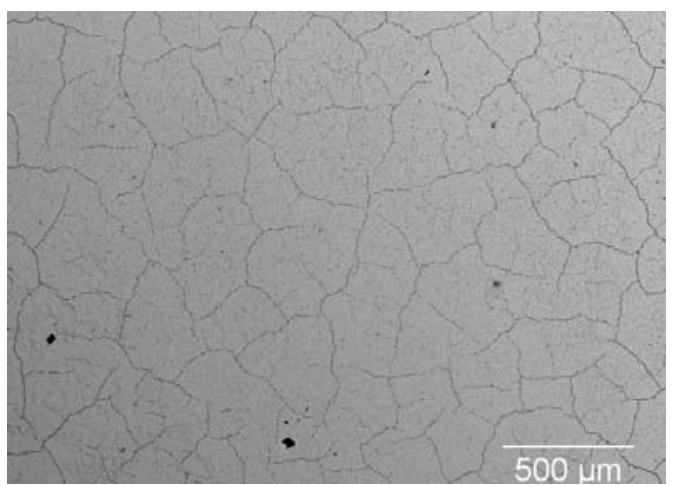

Fig. 3. A network of cracks on W2 (left) and W4 (right) sample developed after PF-6 irradiation.
Table 2. Hardness of the samples before and after irradiation in PF-6

\begin{tabular}{lcc}
\hline & W2 & W4 \\
\hline HV/100 g (surface) & $454 \pm 15$ & $347 \pm 14$ \\
HV/100 g (surface after PF-6) & $391 \pm 20$ & $293 \pm 22$ \\
\hline
\end{tabular}

Only samples without pores were evaluated due to lower surface damage after irradiation; however, also in this case sample hardness might be influenced by the increased surface roughness. Generally, hardness of the samples after irradiation is lower, which might be a consequence of the surface damage such as cracks or recrystallization.

\section{PF-6 irradiation}

The surface morphology of the samples was significantly altered as a result of the exposure in PF-6. The surfaces developed a number of cracks and had an increased roughness (Fig. 3). The cracks formed closed loops with a network of finer cracks within the loops. The cracking is as a result of stress alleviation during the cooling phase of the irradiation experiments. Hirai et al. [14] performed series of experiments with different sample preheating temperatures and applied power density of the heat loading. They concluded that formation of large cracks is caused by brittleness of the tungsten material while finer cracks are related to plastic deformation and subsequent grain boundary ruptures during the cooling phase. Lower density of cracks in the W4 sample might be explained by higher overall porosity that allowed a preferential formation of large and perhaps deeper cracks by coalescence of pores/cracks, leading to a sufficient alleviation of the cooling stresses.

Figure 4 shows the surface morphology of W2-P and W4-P samples after irradiation in PF-6. The figure depicts the difference between the areas containing pores and areas without pores. Due to the lower thermal conductivity and the presence of a gas enclosed in the pores, the areas with showing surface porosity experienced more intensive surface melting and roughening. Moreover, larger pores and consequently growth and collapse of larger bubbles had a pronounced effect on the surface roughness of W4-P sample (Fig. 5, right). Debris from bubble bursting was observed as well. The areas without bubbles developed less serious damage; formation

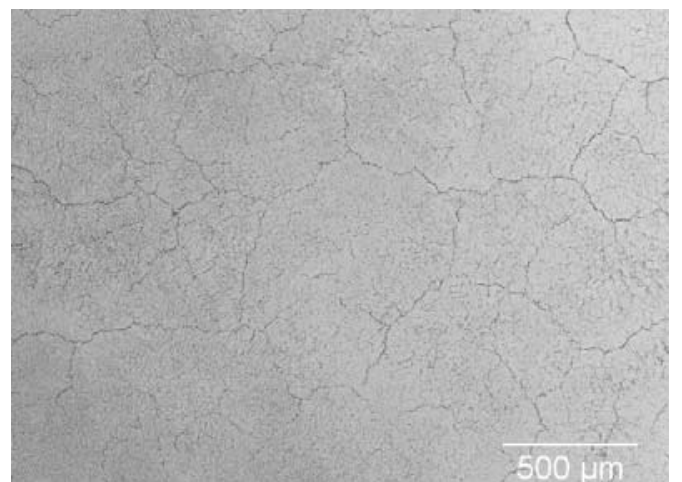



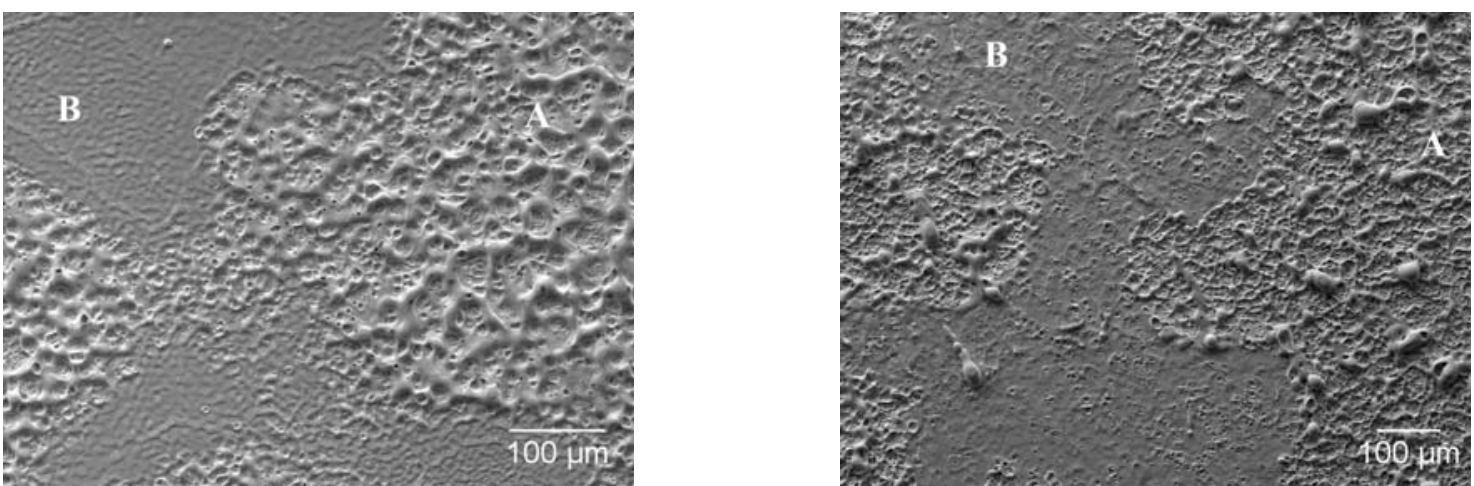

Fig. 4. Roughening and bubble formation on the surface of W2-P (right) and W4-P (left), with pores (A) and without pores (B).

of cracks and blister-like structures was observed (Fig. 5, left). At a higher concentration blisters formed circles. Microstructure of the blisters on the cross section indicates that their formation is related to the near-surface grains (Fig. 6). However, explanation of this phenomenon requires further research. Similar

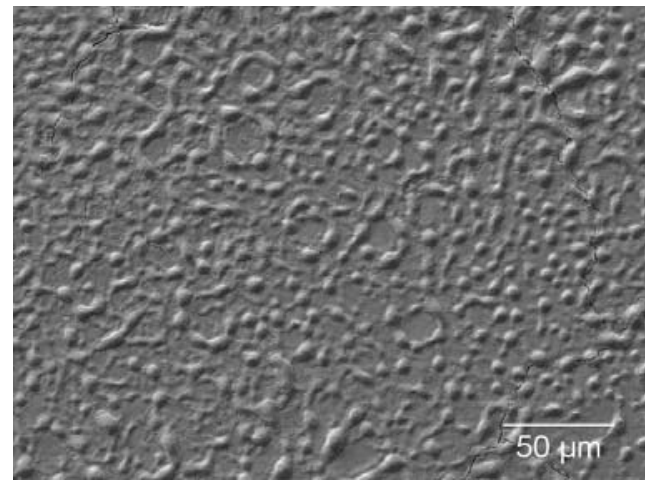

phenomenon was observed in [15], where blisters appeared in a flower-like structure.

The plasma sprayed sample (W-WSPH) developed surface roughness as well (Fig. 7). The main mechanisms behind the relief formation is melting of the splats - preferentialy those with poor bonding to

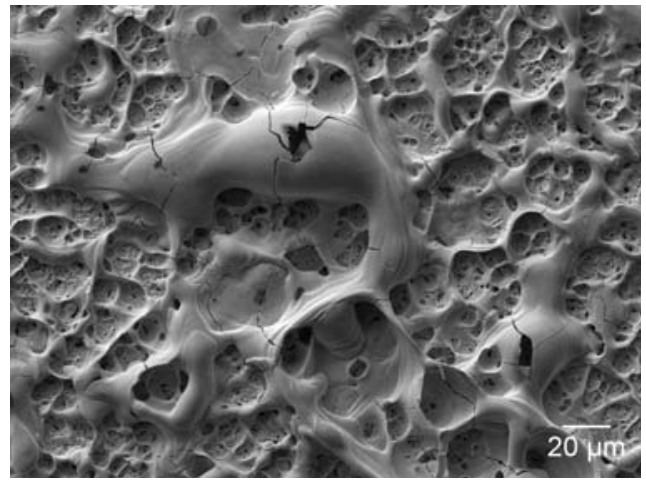

Fig. 5. Blister-like structures on the surface of W2-P (left) and a detailed view of the area with pores (right) on the surface of W4-P, after PF-6 irradiation.

a)

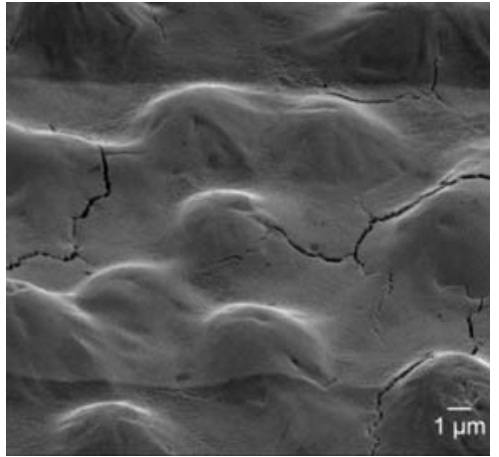

b)
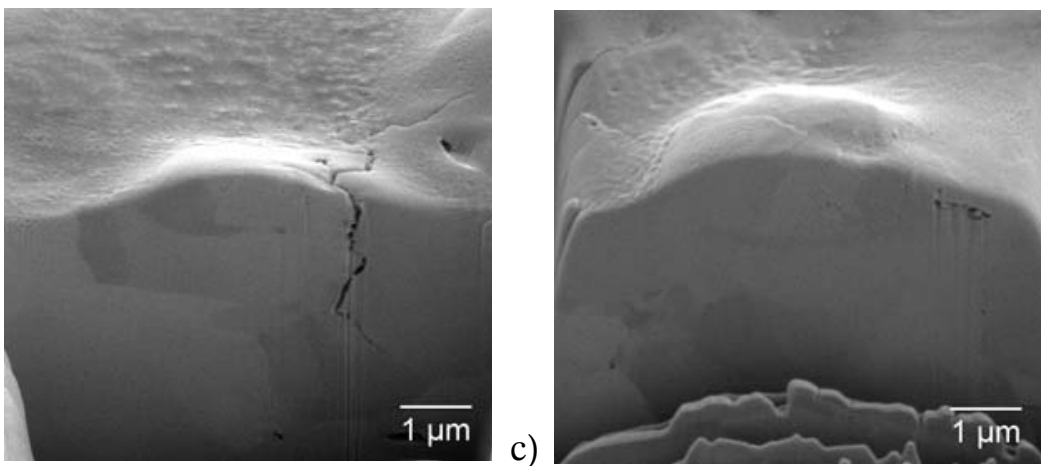

c)

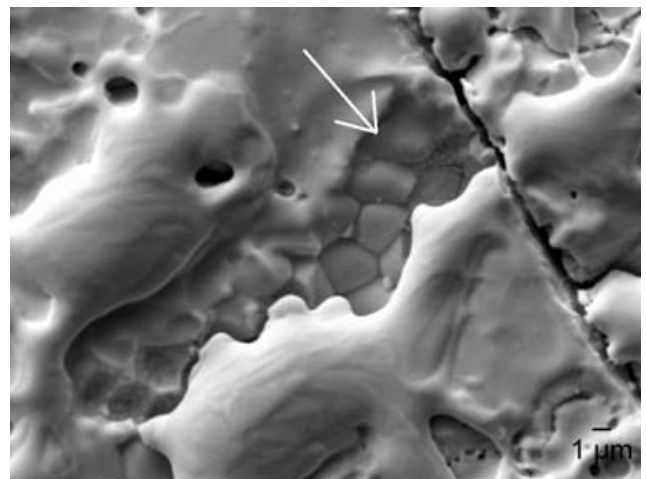

Fig. 7. Surface morphology of the plasma sprayed sample W-WSPH after irradiation in PF-6 (left), detailed view of the molten layer with uncovered columnar crystals (right). 
underlying coating layers, causing a decrease in heat transfer - and surface tension induced shrinkage of the molten tungsten film. Locally preserved smooth surface areas can be the result of weakly bonded splats that lost their cohesion during the thermal expansion of the coating, revealing the surface underneath. On the other hand, large strain tolerance of plasma sprayed coatings caused by mutual splat sliding and opening of the inter-/intrasplat pores [16] resulted in lower crack density on the surface of W-WSPH. Figure 7 (right, arrow) shows the typical columnar grains of the splat preserved underneath the molten layer.

Due to lower thermal properties, the surface of W-WSPH was heavily melted and experienced significant evaporation in the areas of highest heat loading. A number of large spherical and blob-like structures were formed (Fig. 8); some of them solidified unruptured, some of them were torn forming thin tungsten chips. The wrinkled surface of the blobs indicates they did not burst from a gas overpressure; however, they likely experienced a leak of the gas in the molten/semi-molten stage. After solidification the wrinkles became stress concentrators and the fracture developed along them. Above all, structures resembling possible release of gaseous substances from the inside of the material was observed. Figure 9 (left and detail on the right) shows a structure that was created by a passage and coalescence of bubbles through the molten layer on the splat surface. Origin of the gaseous substances is not clear; nevertheless, tungsten boiling bubbles would be expected to be randomly distributed. In [17], the presence of boiling bubbles was explained by melting of impurities originating from the mechanical alloying process. The main impurity to be considered in

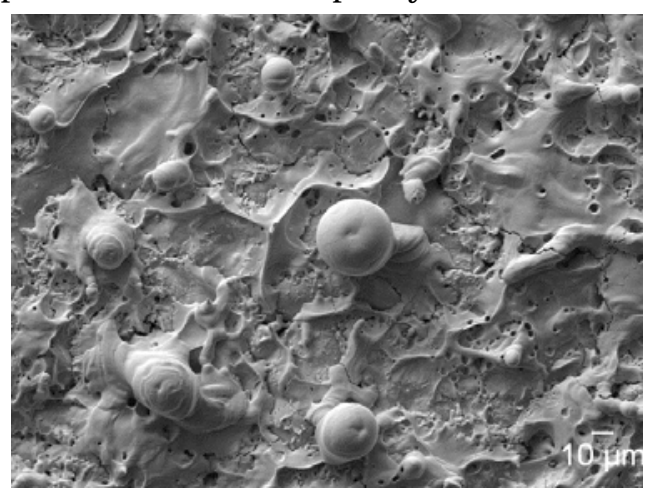

the present samples is tungsten trioxide that has significantly lower melting point than tungsten (ca. $1700^{\circ} \mathrm{C}$ ). Other possible explanation is a release of air entrapped in the intersplat voids. In the case of longer exposures, water vapour arising from reduction of tungsten oxide [18] by hydrogen could be considered as well. Escape of the gas stopped by the solidification process prior to the actual bursting is documented in Fig. 9 (right, circled). Such bubbles/ blisters were recognized in [19] as another source of fusion plasma impurities as the blister skin might exfoliate during subsequent loading.

\section{Laser heat loading}

Besides a number of cracks and roughening, features resembling craters formed by bursting of a bubble were observed on the surfaces of the sintered samples (Fig. 10). Their origin is not clear. Although their appearance was very similar to that previously reported in literature [17], it seem unlikely that the craters result from boiling bubbles. Again, the only impurity expected in the samples is tungsten trioxide. However, the oxide content is very low and is expected to be uniformly distributed as no evidence of oxidized areas was found in the microstructure. Thus, the localized impurity melting would not be the case. Moreover, for all observed craters a small hole was found at their bottom (Fig. 10b-d). Thus it seems the hole was an outlet for a gas entrapped in the material during production/sintering process. The gas was expanding through the molten layer towards the surface where the bubble burst. An analysis of selected craters using the FIB method revealed a void underneath the craters connected

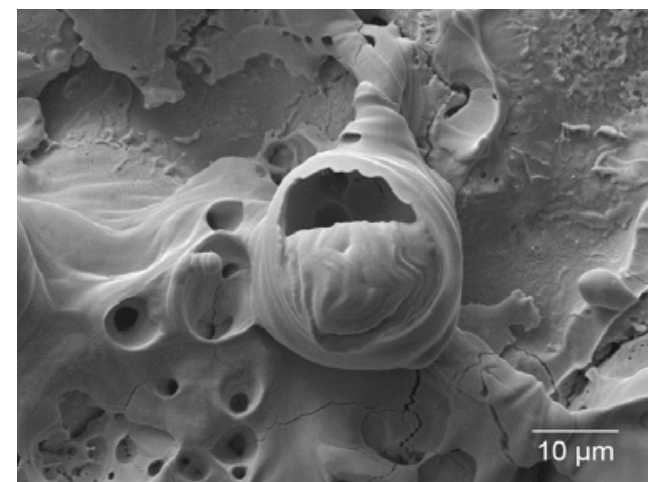

Fig. 8. Area of the highest heat loading on the W-WSPH sample (left) with blob-like bubbles, detail of a blob (right).
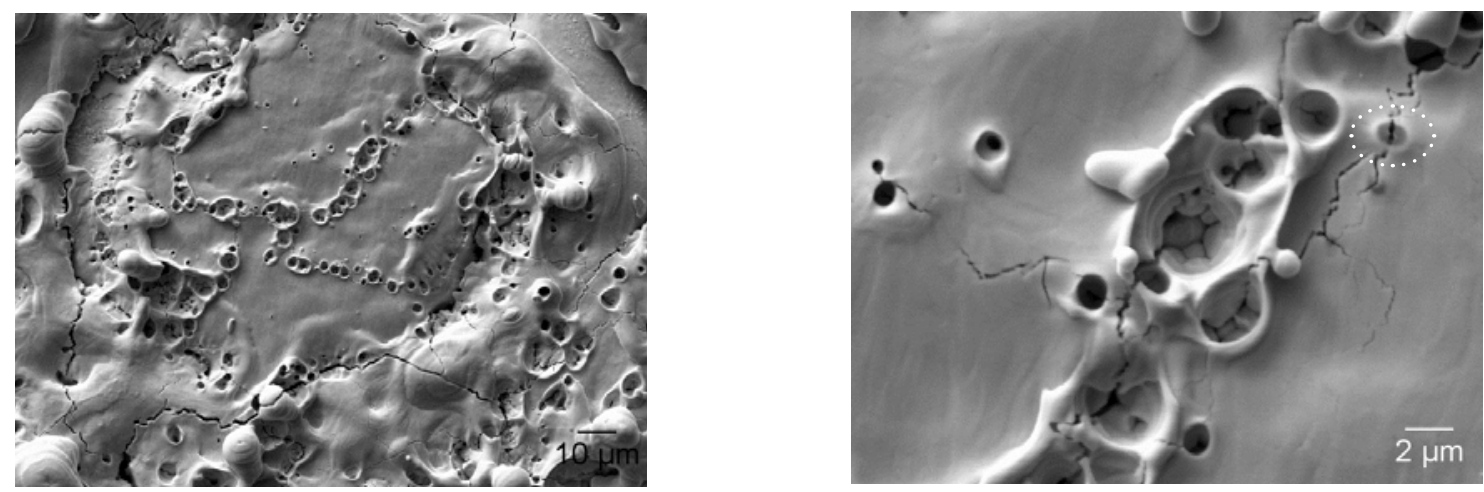

Fig. 9. Splat on the surface of irradiated W-WSPH sample (left), detail of the splat surface (right). 
a)

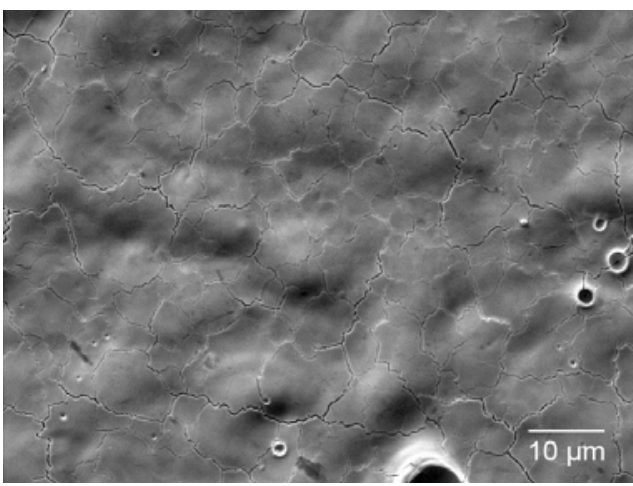

c)

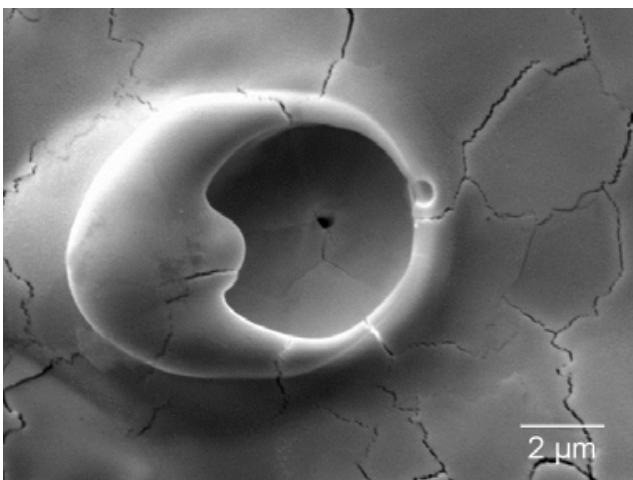

b)

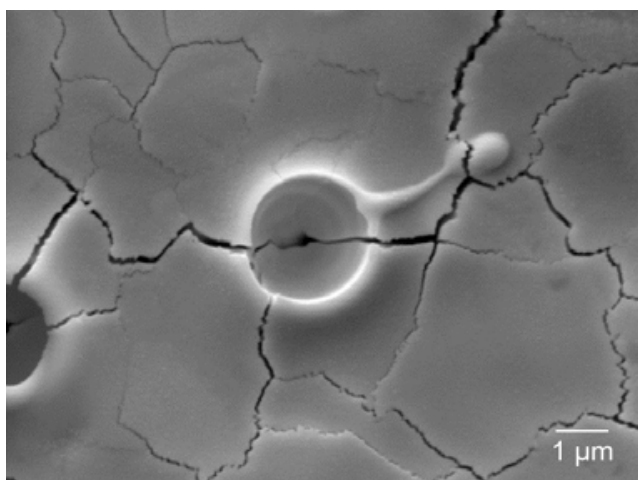

d)

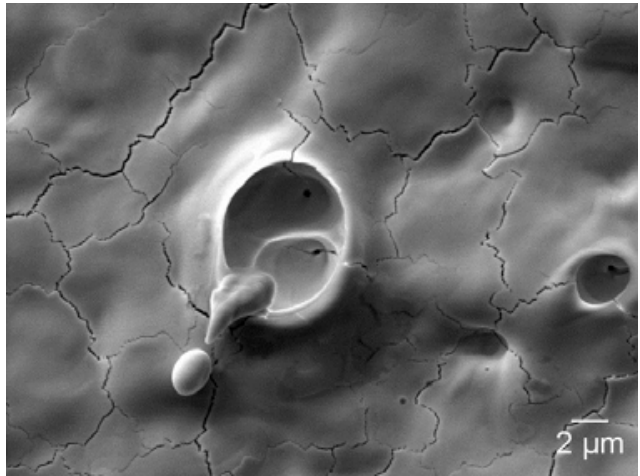

Fig. 10. Surface morphology of the $\mathrm{W} 2$ sample after a laser irradiation (1 shot) and details of craters formed after a bubble burst: a) surface after heat loading by laser; b), c) and d) the crater on the surface.

to the surface via a hole (Fig. 11), supporting the hypothesis of the hot gas expansion from a closed void/pore. Thus, the presence of closed micropores in plasma facing materials represents another potential source of surface erosion (Figs. 10b-d) and fusion plasma contamination by the escaping gases and by the ablated material.

Figure 12 shows the difference between the behavior of a pore containing areas with and without pores. Again, it can be seen that the polished areas

a)

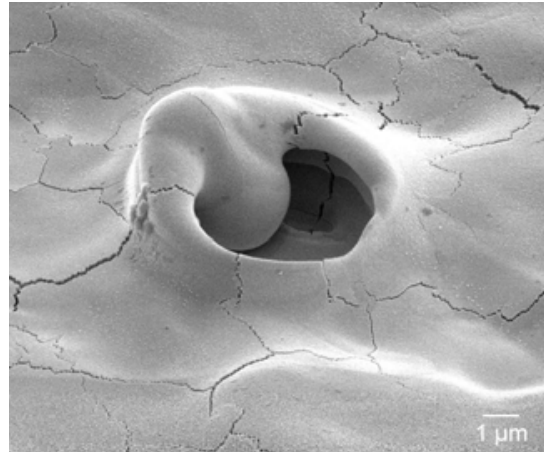

show much less damage (light patches in the laser modified area - circled in Fig. 12). The area with pores showed signs of significant melting, evaporation, bubble formation and bubble collapsing. The area without pores developed minor surface roughening and sparse formation of craters (detailed structure in Fig. 12, right).

Repeated heat loading of W2-P sample (10 laser shots) led to serious melting and evaporation. Figure 13 shows the relief of a remelted/resolidified

b)
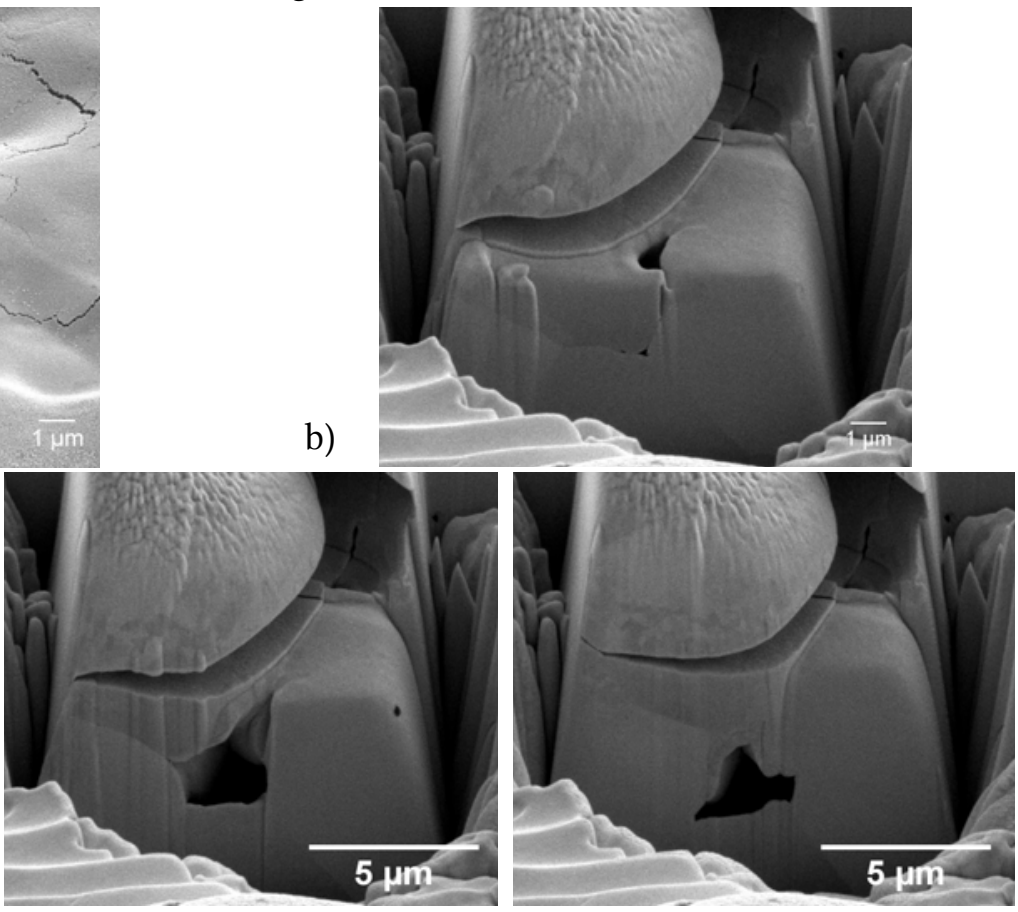

c)

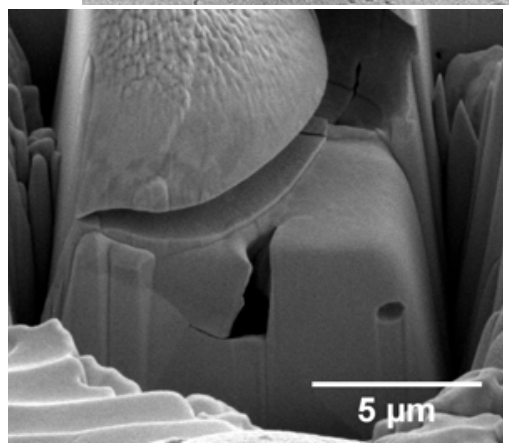

Fig. 11. A void underneath the bottom of a crater found on the surface of the W2 sample after laser irradiation: the crater (a), a hole found in the bottom of the crater (b), the size and the shape of the void revealed by the FIB method (c). 

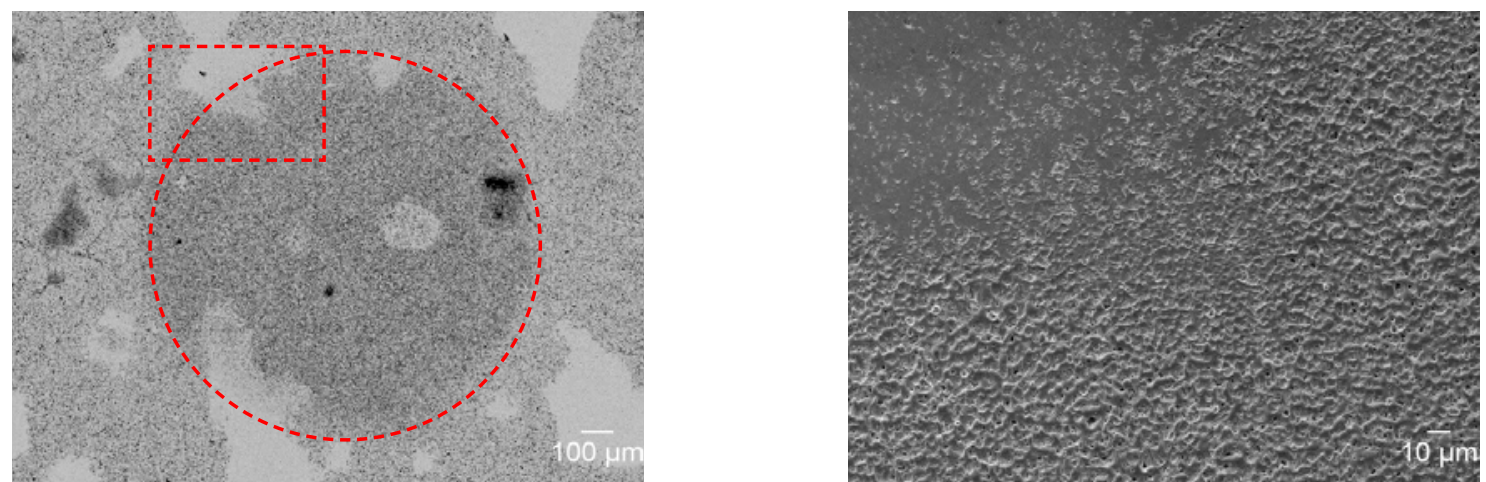

Fig. 12. The surface morphology of the W4-P sample after 1 laser shot (left, circled), detailed view of a region in the figure on the left (right).
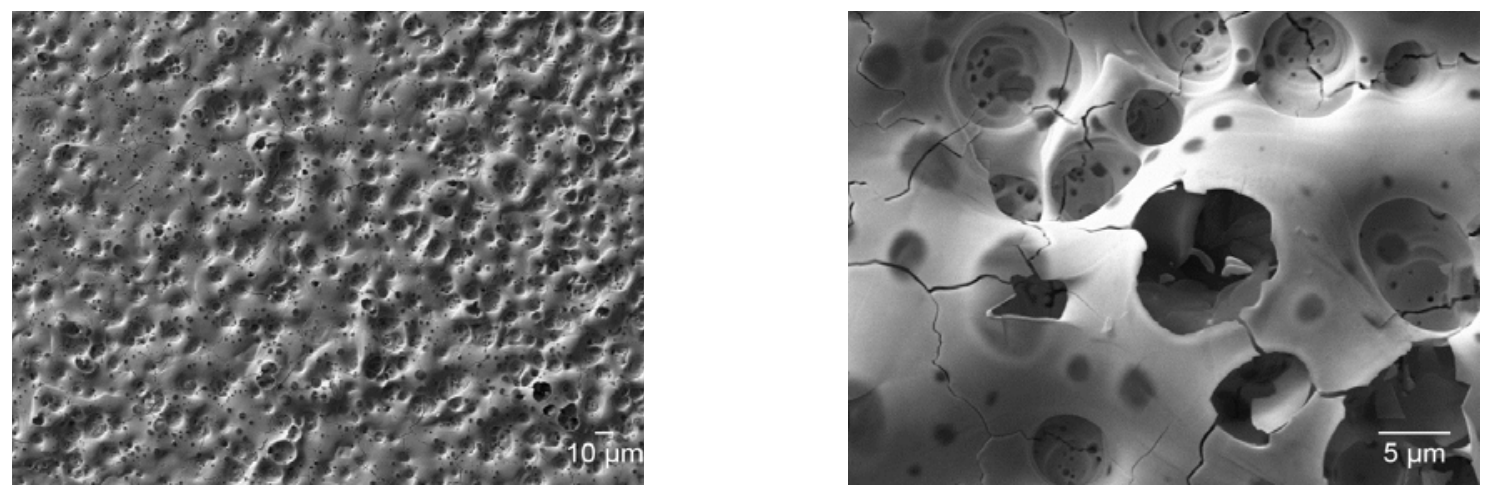

Fig. 13. The surface morphology of the W2-P sample after laser irradiation (10 shots), in the region containing pores (left), detailed view of the region (right).

surface with bubbles. The thin walls of larger bubbles tend to collapse, forming tungsten chips and dust. A number of smaller bubbles inside the tungsten just beneath the surface can be also seen. Further loading would likely cause their growth and subsequent collapse, forming more chips and dust.

\section{Conclusions}

In the presented work, the response of tungsten with porous surface layer simulating helium/hydrogen bubbles to thermal and particle loading was examined. Tungsten samples were prepared by spark plasma sintering. A tungsten coating containing an intrinsic porosity and prepared by hybrid argon/water stabilized plasma spraying was studied as well.

The heat and particle loading was significantly more destructive for samples with bubbles. The bubble growth and bursting resulted in:

- ejection of the material from the surface,

- formation of tungsten chips,

- an increased surface roughness,

when compared to the response of the samples without bubbles. The effect of surface roughening and erosion was more pronounced for samples with larger initial bubble size.

Similar features, i.e. roughening and formation of thin tungsten chips were observed on plasma sprayed tungsten. Both the loss of material formed by the bubble bursting or by the chipping off could increase the impurity content in the fusion plasma and thus negatively influence the performance of the fusion device.
The surface modifications were significantly lower for the samples without surface bubbles. Surface roughening and formation of crack network was the major damage developed in the material. Sparse occurrence of craters with dimensions of several micrometers was observed. A detailed study of the craters helped to identify another mechanism of surface erosion originating from closed micropores.

Acknowledgments. This work was supported by the Czech Science Foundation through grant no. 14$12837 \mathrm{~S}$ and partly supported by the IAEA CRP RC16954 and RC-16956 grants, and by Polish Ministry of Science and Higher Education within the framework of the financial resources in the year 2014 allocated for the realization of the international co-financed projects.

\section{References}

1. Stork, D., Agostini, P., Boutard, J. -L., Buckthorpe, D., Diegele, E., Dudarev, S. L., English, C., Federici, G., Gilbert, M. R., Gonzalez, S., Ibarra, A., Linsmeier, C., Puma, A. L., Marbach, G., Packer, L. W., Raj, B., Rieth, M., Tran, M. Q., Ward, D. J., \& Zinkle, S. J. (2014). Materials R\&D for a timely DEMO: Key findings and recommendations of the EU Roadmap Materials Assessment Group. Fusion Eng. Des., 89(7/8), 1586-1594. http://dx.doi.org/10.1016/j. fusengdes.2013.11.007.

2. Wirtz, M., Linke, J., Pintsuk, G., Singheiser, L., \& Zlobinski, M. (2013). Comparison of thermal shock damages induced by different simulation methods on 
tungsten. J. Nucl. Mater., 438(Suppl.), S833-S836. http://dx.doi.org/10.1016/j.jnucmat.2013.01.180.

3. Linke, J. (2008). High heat flux performance of plasma facing materials and components under service conditions in future fusion reactors. Trans. Fusion Sci. Technol., 53, S278-S287.

4. Garkusha, I. E., Arkhipov, N. I., Klimov, N. S., Makhlaj, V. A., Safronov, V. M., Landman, I., \& Tereshin, V. I. (2009). The latest results from ELM-simulation experiments in plasma accelerators. Phys. Scripta, T138, 014054. DOI: 10.1088/0031-8949/2009/ T138/014054.

5. Shu, W. M., Nakamichi, M., Alimov, V. K., Luo, G. N., Isobe, K., \& Yamanishi, T. (2009). Deuterium retention, blistering and local melting at tungsten exposed to high-fluence deuterium plasma. J. Nucl. Mater., 390/391, 1017-1021. http://dx.doi.org/10.1016/j. jnucmat.2009.01.267.

6. Morgan, T. W., van Eden, G. G., de Kruif, T. M., van den Berg, M. A., Matějíček, J., Chráska, T., \& De Temmerman, G. (2014). ELM-induced melting: assessment of shallow melt layer damage and the power handling capability of tungsten in a linear plasma device. Phys. Scripta, T159, 014022. DOI: 10.1088/0031-8949/2014/T159/014022.

7. Shirokova, V., Laas, T., Ainsaar, A., Priimets, J., Ugaste, Ü., Demina, E. V., Pimenov, V. N., Maslyaev, S. A., Dubrovsky, A. V., Gribkov, V. A., Scholz, M., \& Mikli, V. (2013). Comparison of damages in tungsten and tungsten doped with lanthanum-oxide exposed to dense deuterium plasma shots. J. Nucl. Mater., 43(1/3), 181-188. http://dx.doi.org/10.1016/j.jnucmat.2012.12.027.

8. Riesch, J., Buffiere, J. Y., Höschen, T., di Michiel, M., Scheel, M., Linsmeier, C., \& You, J. H. (2013). In situ synchrotron tomography estimation of toughening effect by semi-ductile fibre reinforcement in a tungsten-fibre-reinforced tungsten composite system. Acta Mater., 61(19), 7060-7071. http://dx.doi. org/10.1016/j.actamat.2013.07.035.

9. Nishijima, D., Sugimoto, T., Iwakiri, H., Ye, M. Y., Ohno, N., Yoshida, N., \& Takamura, S. (2005). Characteristic changes of deuterium retention on tungsten surfaces due to low-energy helium plasma pre-exposure. J. Nucl. Mater., 337/339, 927-931. http://dx.doi.org/10.1016/j.jnucmat.2004.10.011.

10. Yuan, Y., Greuner, H., Böswirth, B., Linsmeier, C., Luo, G. N., Fu, B. Q., Xu, H. Y., Shen, Z. J., \& Liu, W. (2013). Surface modification of molten W exposed to high heat flux helium neutral beams. J. Nucl. $\mathrm{Ma}$ - ter., 437(1/3), 297-302. http://dx.doi.org/10.1016/j. jnucmat.2013.02.043.

11. Ueda, Y., Coenen, J. W., De Temmerman, G., Doerner, R. P., Linke, J., Philipps, V., \& Tsitrone, E. (2014). Research status and issues of tungsten plasma facing materials for ITER and beyond. Fusion Eng. Des., 89(7/8), 901-906. http://dx.doi.org/10.1016/j. fusengdes.2014.02.078.

12. Shin, K., Shuichi, T., Noriyasu, O., Dai, N., Hirotomo, I., \& Naoaki, Y. (2007). Sub-ms laser pulse irradiation on tungsten target damaged by exposure to helium plasma. Nucl. Fusion, 47(9), 1358-1366. DOI: 10.1088/0029-5515/47/9/038.

13. Matějíček, J., Kavka, T., Bertolissi, G., Ctibor, P., Vilémová, M., Mušálek, R., \& Nevrlá, B. (2013). The role of spraying parameters and inert gas shrouding in hybrid water-argon plasma spraying of tungsten and copper for nuclear fusion applications. J. Therm. Spray Technol., 22(5), 744-755

14. Hirai, T., Pintsuk, G., Linke, J., \& Batilliot, M. (2009). Cracking failure study of ITER-reference tungsten grade under single pulse thermal shock loads at elevated temperatures. J. Nucl. Mater., 390/391, 751-754. http://dx.doi.org/10.1016/j.jnucmat.2009.01.313.

15. Shu, W. M., Kawasuso, A., \& Yamanishi, T. (2009). Recent findings on blistering and deuterium retention in tungsten exposed to high-fluence deuterium plasma. J. Nucl. Mater., 386/388, 356-359. http:// dx.doi.org/10.1016/j.jnucmat.2008.12.129.

16. Mušálek, R., Matějíček, J., Vilémová, M., \& Kovářík, O. (2010). Non-linear mechanical behavior of plasma sprayed alumina under mechanical and thermal loading. J. Therm. Spray Technol., 19(1/2), 422-428. 10.1007/s11666-009-9362-x.

17. Tan, J., Zhou, Z.-j., Zhu, X.-p., Guo, S.-q., Qu, D.-d., Lei, M.-k., \& Ge, C.-c. (2012). Evaluation of ultrafine grained tungsten under transient high heat flux by high-intensity pulsed ion beam. Trans. Nonferrous Met. Soc. China., 22(5), 1081-1085. http://dx.doi. org/10.1016/S1003-6326(11)61286-7.

18. Eliáš, M., Frgala, Z., Kudrle, V., Janča, J., \& Brožek, V. (2004). Low temperature metallurgy of tungsten in plasma reactors. J. Adv. Oxidation Technol., 7(1), 91-97.

19. Ohno, N., Kajita, S., Nishijima, D., \& Takamura, S. (2007). Surface modification at tungsten and tungsten coated graphite due to low energy and high fluence plasma and laser pulse irradiation. J. Nucl. Mater., 363/365, 1153-1159. http://dx.doi.org/10.1016/j. jnucmat.2007.01.148. 